\title{
إشتقاق الألفاظ و إعجاز معانيها في القرآن الكريم
}

\section{Rahmat Ramadan Bahua ${ }^{1}$ Ibnu Rawandi Hula ${ }^{2}$ Hasim Halim $^{3}$}

1. Rahmatramadanbahua@gmail.com, Alumni Sastra Arab Fakultas Ilmu Budaya Universitas Muhammadiyah Gorotalo

2.Ibrah@gmail.com. Dosen IAIN Sultan Amai Gorontalo

3. Dosen Sastra Arab, Fakultas Ilmu Budaya, UMGo

\section{تجريد البحث}

هذا البحث يتكلم عن "إشتقاق الألفاظ القرآنية و إعجاز معانيها "دراسة تحليلية الدلالية".

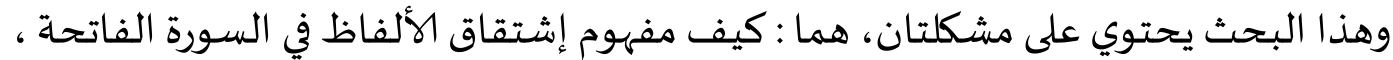

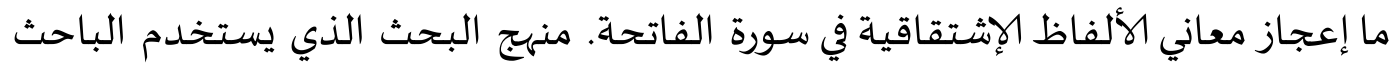

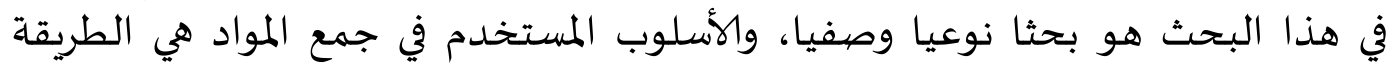
المكتبية، و أما مصادر المواد المبحوثة المستخدمة نوعان هوان هما مصددر المواد الأولية و مصددر

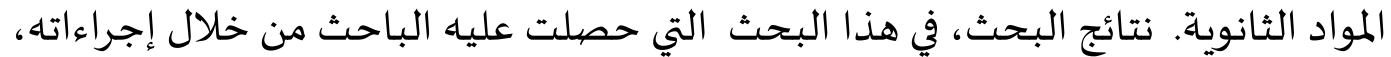

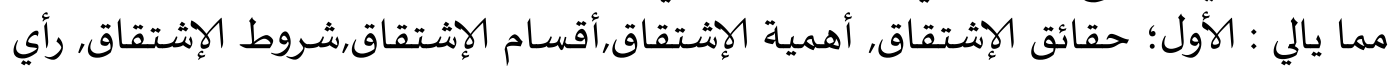

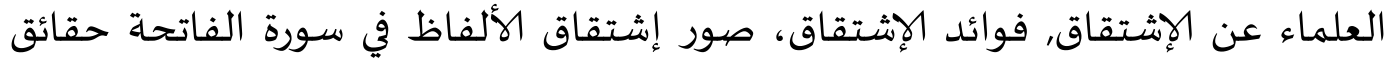

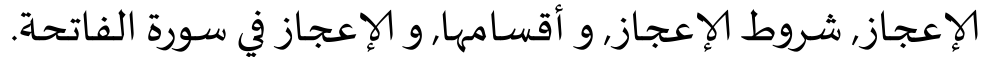

\section{الكلمات الرئيسية : إشـتقاق, إعجاز, معاني, دلالية}

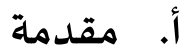

القرآن الكريم هو كتاب اللغة العربية الخالد فقد حفظ هذه اللغة من الاندثار

والانقراض ووصل ماضي هذه الأمة بحاضرها فيستطيع العربي أن يفهم ما كتبه أجداده قبل آلاف السـين وهذه مزية لهذه الأمة بفضل هذا الكتاب الكريم على غيرها من الأمم كما عمل على نشرها في مناطق واسعة من العالم فلا يوجد قطر في كافة أرجاء المعمورة إلا وفياه من يتكلم العربية لغة الدين والحضـارة الإسلامية، كما أغناها بالعبارات والمصطلحات الجديدة كالصوم والصهلاة وغيرها، والأهم من كل ذلك أنها وحدّ لهجاتها في لهجـة واحدة فأصببحت لغة

\section{'A Jamiy Jurnal Bahasa dan Sastra Arab}

Volume 08, No. 2, September 2019 ISSN: 2252-9926 (Print), ISSN: 2657-2206 (Online) 
172

العالم والدين والتفاهم بين الناس. وهذه المزايا التي أعطاها القرآن لهذه اللغة جعلتها تسـاهم في فهم هذا الكتاب الكريم.

الاشتقاق هوتوليد الألفاظ بعضها من بعض. الاشتقاق صيدى ما في العقلية العربية

من خصائص التفكير المنطقي والعلمي. هذه الطريقة حيوية توليدية أشباء بطريقة توالد الأحياء، وليست آلية جامدة، خلاف طرقة اللغات الأخرى التي تكون طربة آلية أكثر منها توليدية، وبذلك لم ينقطع سيل الألفاظ الجديدة في اللغة العربية. وكان الاشتقاق كذلك طريقاً للتجديد والتنويع الفني .اشتقاق الشئ بنياناه من المرتجل و اشتقاق الكلام الأخذ فيه يمينا وشمالا و الإشتقاق الحرف من الحرف. قال صاحب المعجم الوسيط في تعريف : الاشتقاق في علوم العربية: صوغ كلمة من أخرى على حسب قوانين الصرف. وعرَّفه الشـوكاني بقوله: "أن تجد بين اللفظين تناسبًا في المعنى والتركيب، فترد أحدهما إلى الآخر. والاشتقاق أخْذُ صيغة من أخرى مع اتفاقهما معنىً ومادةً أصلية، وهيئة تركيب لها، ليُّل بالثانية على معنى الأصيل بزيادة مفيدة، لأجلها اختلفا حروفاً أو هيئة، كضيارب من ضرب، وطريق معرفته تقليب تصاريف الكلمة حتى يرجع منها المى صيغة هي أصل الصِيّيخ دلالة اطراداً وحروفا غالباً: كضرب فإنه دال على مطلق الضرب فقط أما ضارب، ومضروب، وَضضْرب واضرب فكلُّها أكثر دلالة وأكثر حروفاً، وضرب الماضي مساوٍ حروفاً وأكثرُ دلالة، وكلّها مشتركة في (ض، ب، ر) وفي هيئة تركيها، وهذا هو الاشتقاق الأصْغَرَ المحتجُّ باه، وأما الأكبر فيحفظ فيه المادّة دون الهيئة فيجعل (ق، و، ل) و (و، ل، ق) و (و، ق، ل) و (ل، ق، و) تقاليهها الستاة بمعنى الخَّفة والسـرعة، وهذا مما ابتدعَه الامام أبو الفتح ابن جني، وكان شيخها أبو علي الفارسي يأنس باه يسيراً، وليس معتمداً في اللغة، ولا يصحّ أن يُستنبط به اشتقاق في لغة العرب، ثم التغييرات بين الأصل المشتق منه والفرع المشتق خمسة عشر ذكرها السيوطي في المزهر، وإذا تردّدت الكلمة بين أصِلين في الشتقاق طلب الترجيح وله

$$
\text { وجوه ذكرها في المزهر أيضياً، وهي تسعة. }
$$

\section{'A Jamiy Jurnal Bahasa dan Sastra Arab}

Volume 08, No. 2, September 2019 ISSN: 2252-9926 (Print), ISSN: 2657-2206 (Online) 
173

والأعلام غالهها منقولٌ بخلاف أسماء الأجناس، فلذلك قلَّ أن يُشتقّ اسم جنس لأنه أصل مُرْتَجل قال بعضهه: فإن صيح فيه اشتقاقُ حمل عليه قيل: ومنه غُرَاب من الاغتراب

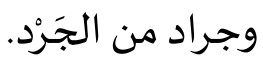

والأصل في الاشتقاق أن يكون من المصادر، وأصدقُ ما يكون في الأفعال المزيدة والصفات منها، وأسماء المصادر، والزّمان والمكان ويغلبُ في العَلَم، والتصريف أعمُّ من الاشتقاق، لأن بناء مثل قردد من الضّرب يسمى تصريفاً (7 ع/ ... ) ولا يسمى اشتقاقاً، لأنه

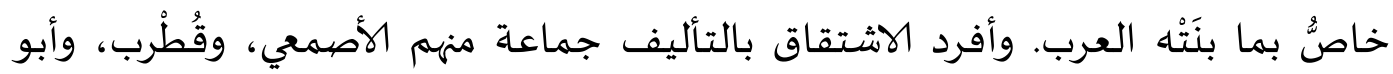
الحسن الأخفش، وأبو نصر الباهلي، والمفضّل بن سلمة، والمبّرد، وابن دريد، والزَّجاج، وابن السراج، والرماني، والنحاس، وابن خالويه، ومما ينبغي أن يُحْذَر كل الحذَر أنْ يَشْنَقََّّ من لغة العرب شيء من لغة العَجَم، فيكون بمنزلة مَن ادَّعى أن الطير وَلَّد الحوت. مناهج البحث

في هذه الرسالة استحدم الكاتب بحثا نوعيا وصفيا بالنسبة لنوع البحث، وأما

البحث النوعيّ الوصفيّ فهو إجراء البحوث التي تنتج بيانات وصفية و شكل خطاب في الكلمات المكتوبة أو المنطوقة لشعب السلوك المشاهد ا ـوأما تقريب البحث استخدم الكاتب طريقة تحليلية بلاغية تطبقية. وهذا التقريب يسعى إلى أكثر التحليل الوثيق في النصوص المكتوبة وما يتضمن بها. في كتابة هذا البحث، سلك الباحث مرحلتين كما يالي :

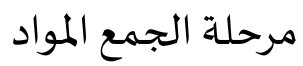
في هذه المرحلة، قام الباحث بجمع المواد المبحوثة من مصادر متفرقة، سواء كانت باللغة العربية أم باللغة الإندنيسية، باستعمال الطريقة المكتبية، وبها أيضا قام الباحث

$$
\text { اليكسي موليونج، طرق البحث النوعيّ، (باندنج : رامج روصدا كاريا،...) )، ص.ب }
$$

\section{'A Jamiy Jurnal Bahasa dan Sastra Arab}

Volume 08, No. 2, September 2019 ISSN: 2252-9926 (Print), ISSN: 2657-2206 (Online) 
174

بقراءة المصادر والمراجع المتعلّقة بالموضوع. ثم قام بعد ذلك بجمع المواد المدرسية عن طرق النقل والاقتباش منها. مرحلة تنظيم المواد و تحليلها بعد أن جمع الكاتب المواد المطلوبة، قام بعد ذلك بتنظيمها و تبويها. وبعد ذاك، قام الكاتب بتحليلها تحليلا علميا ليتصل إلى خلاصية علمية حول هذا الموضوع. في سبيل تحليل المواد، استخدم الكاتب الطرق الآتية :

الطريقة القياسية : و هي القيام بإيجاد الخلاصية من الأشياء العامة إلى الأشياء الخاصة. ا. الطريقة الإستقرائية : و هي القيام با استنتاج النتائج من الأمور الخاصة إلى الأمور العامة. r. الطريقة المقارنة : و هس طريقة تحليل المواد بواسطة مقارنة عن الآراء في البلاغاة و تعبير التي تتعلق بهذا الموضوع المبحوث ثم القيام با استنتاج النتائج منها.

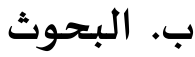
1. حقائق الإشتقاق

الاشتقاق في اللغة هو أخذ شيء من شيء. قال ابن منظور:اشتقاق الشيء: بنياناه من

المرتجل، واشتقاق الكلام: الأخذ باه يميناً وشمالاً، واشتقاق الحرف من الحرف: أخذه منه. الاشتقاق هو الأخذ في الكلام وفي الخصومة مع ترك القصد, و فرس أشق, و قد اشتق في عدوه يمينا وشمالا, هذا ما ذكره الخليل. و ذكر الجوهري أن الإشتقاق هو أخذ في الكلام و في الخصومة يمينا و شمالا مع ترك القصد, و اشتقاق الحرف من الحرف أخذه منه. و نقل الأزهري عن الليث أنه قال : في عدوه كأنه يميل في أحد شقية. و نص الزبيدي علي أن الإشتقاق أخذ شق الثيء و هو نصفه, و الإشتقاق بيان الثيء من المرتجل, ثم أتي بكلام الجوهري و قال بعد ذلك (و مناه سمي أخذ الكلمة من الكلمة اشتقاقا).

\section{'A Jamiy Jurnal Bahasa dan Sastra Arab}

Volume 08, No. 2, September 2019 ISSN: 2252-9926 (Print), ISSN: 2657-2206 (Online) 
175

والاشتقاق يرجع في الأصل إلى مادة ( الشين و القاف المضاعفة ) ( شقق ) معناه

كما ورد في المعاجم اللغوية ( الصدع و البينونة و الخلاف و الفصل و نحو ذلك ). فقد ذكر

الخليل أن (الشتق) مصدر شققت, و الشق غير بائن و لا نا فذ, و لبصيدع ربما يكون من وجه.

و الكلمات التي أخذت من هذا الجذر الشين و القاف يحوم جميعها حول معن الصدع و

الإنشقاق و في هذا يقول ابن فارس : الشين والقاف أصل واحد صديح يـلنُعلي انصداع في

الشيء ثم يكمل عليه ويشتق منـه علي معنى الاستعارة, تقول : شققت الشيء أشقه شقا إذا صدعتاه وبيده شقوق وبالدابة شقاق والأصل واحد.

\begin{tabular}{|c|c|c|c|c|}
\hline \multicolumn{5}{|c|}{ الإشتقاق في كلمة بسم } \\
\hline الشـرح & إعجازدلالى & صور الإشتقاق & أصلاه & كلممة \\
\hline وهذه الكلمة & "بـآسنسمِ"معياريَّا & مشتق من & يَبِسِمِ - -بسَمَ & بسم \\
\hline تكتب عادة & تفرض نفستها & السمة وهو & بَسنسمًا - & \\
\hline بالألف أي & حاليَّا على الأقل & العلامة الدالة & باسِم فهو & \\
\hline "باسم". & لتيسير التّعلّْم & على المسسى. أو & & \\
\hline بدون وكتابتها & والتّعليم. & أنها مشتق من & & \\
\hline ألف استثناء & & السمو بمعنى & & \\
\hline جهاة وخاصيّة من & & الرفعة & & \\
\hline بالله تعالى من & & & & \\
\hline جهة أخرى فلا & & & & \\
\hline تكتب بدون ألف & & & & \\
\hline حين تكون & & & & \\
\hline متبوعة بغير & & & & \\
\hline .اسم الله & & & & \\
\hline
\end{tabular}

\section{'A Jamiy Jurnal Bahasa dan Sastra Arab}

Volume 08, No. 2, September 2019 ISSN: 2252-9926 (Print), ISSN: 2657-2206 (Online) 
176

الإشتقاق في كلمة الله

\begin{tabular}{|c|c|c|c|c|}
\hline الشرح & إعجاز دلالى & صورالإشتقاق & أصله & كلمة \\
\hline "آللّه" آسمَّ & "آللّه" آسمَّ & مشتق من & \multirow[t]{7}{*}{ إלاله } & الله \\
\hline مُفرَدُ لا يُثنى وََا & مُفرَدَد لا يُثَنّى ولَا & السمة وهو & & \\
\hline يُجْمَع، بخلاف & يُجمَع، بخلاف & العلامة الدالة & & \\
\hline آسم "إلَاه" الذي & آسم "إلاهه" الذي & على المسنى. أو & & \\
\hline يُشنىّى على & يُثيثنى على & أنه مشتق من & & \\
\hline "إلآَهَانِ" ويُجمَع & "إِآَهَانِ" ويُجمَع & السمو بمعنى & & \\
\hline \multirow[t]{2}{*}{ على "آلَّهَه" } & على "آلهَهَة" & الرفعة & & \\
\hline & & & \multicolumn{2}{|c|}{ الإشتقاق في كلمة الرحمن } \\
\hline الشرح & إعجازدلالى & صورالإشتقاق & أصله & كلمة \\
\hline فالرحمن هو & "الرَّحْمَان" & مشتق من & رحِمَ - يَرحَم & الرحمن \\
\hline الرب الذى علم & مُفرَدًا خاصٌُ & الرحمة الذي & & \\
\hline وخلق كل شىء & باللّه تعالى & وسعت رحمتُه & & \\
\hline أى هو الذى & بصفتا الذي & كلَّ شيء & & \\
\hline أعطى كل شىء & يَشَملُ برحمته & & & \\
\hline النفع اللازم له & وفضله كل & & & \\
\hline فهو فاتح & المخلوقات دُنيًا & & & \\
\hline الرحمة أى & وآخرةً & & & \\
\hline معطى النفع & & & & \\
\hline مصداقة & & & & \\
\hline
\end{tabular}

\footnotetext{
'A Jamiy Jurnal Bahasa dan Sastra Arab

Volume 08, No. 2, September 2019 ISSN: 2252-9926 (Print), ISSN: 2657-2206 (Online)
} 
177

الإشتقاق في كلمة الرحيم

\begin{tabular}{|c|c|c|c|c|}
\hline الشرح & إعجـازدلالى & صيورالإشـتقاق & أصله & كلممة \\
\hline فالرحيم هو ذو & "ارََّحْمَة" & مشتق أيضيا من & رحِمَ - يَرحَم & الرحيم \\
\hline الرحمة & تختصّ بالدّلالة & الرحمة ومعناه : & & \\
\hline الواصلة:؛ & على (الإنعام في & الرَّفيق بالمؤمنين & & \\
\hline فالرحمن & قُرْبهاه وسَعتـها) & ، والعاطف على & & \\
\hline وصفف؛؛ والرحيم & & خلقاء باللِّزق & & \\
\hline فعلُه؛ ولو أنه & & & & \\
\hline جيء بـ"الرحمنن" & & & & \\
\hline وحدَه، أو & & & & \\
\hline ب" بالرحيم" & & & & \\
\hline وحده؛ لشمل & & & & \\
\hline الوصف والفعل & & & & \\
\hline
\end{tabular}

الإشتقاق في كلمة الحمد الله

\begin{tabular}{|c|c|c|c|c|}
\hline الشرح & إعجازدلالى & صور الإشتقاق & أصلله & كلمة \\
\hline (آلحمد للّلهِ) & أنّ "آلحمدد" & حامد، معنـه : & حمِدَ - يَحمَد & الحممد لله \\
\hline بدلا من (لِلّه & مقصـورٌ على & الثناءُ بالجميل & & \\
\hline الحمدُ) أو & آللّه بصفتـه & & & \\
\hline (أحسمَدُ آللّلَهَ) أو & الذي يُحمَدُ في & & & \\
\hline (حَمْدًَا للَّهِ) يَدُلَّ & السّرَّاء والضِّرَّاء & & & \\
\hline على أنّها ليست & على سَـواءٍ & & & \\
\hline من كلام البشر: & & & & \\
\hline فتقديمُ & & & & \\
\hline "الحمد" (كآسمي & & & & \\
\hline
\end{tabular}

\section{'A Jamiy Jurnal Bahasa dan Sastra Arab}

Volume 08, No. 2, September 2019 ISSN: 2252-9926 (Print), ISSN: 2657-2206 (Online) 
178

جنس) وتأخير

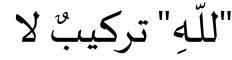

يُفيد فقط أنّ تَّبَ

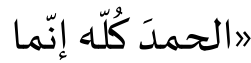

يكون للّه وحده كله إنما

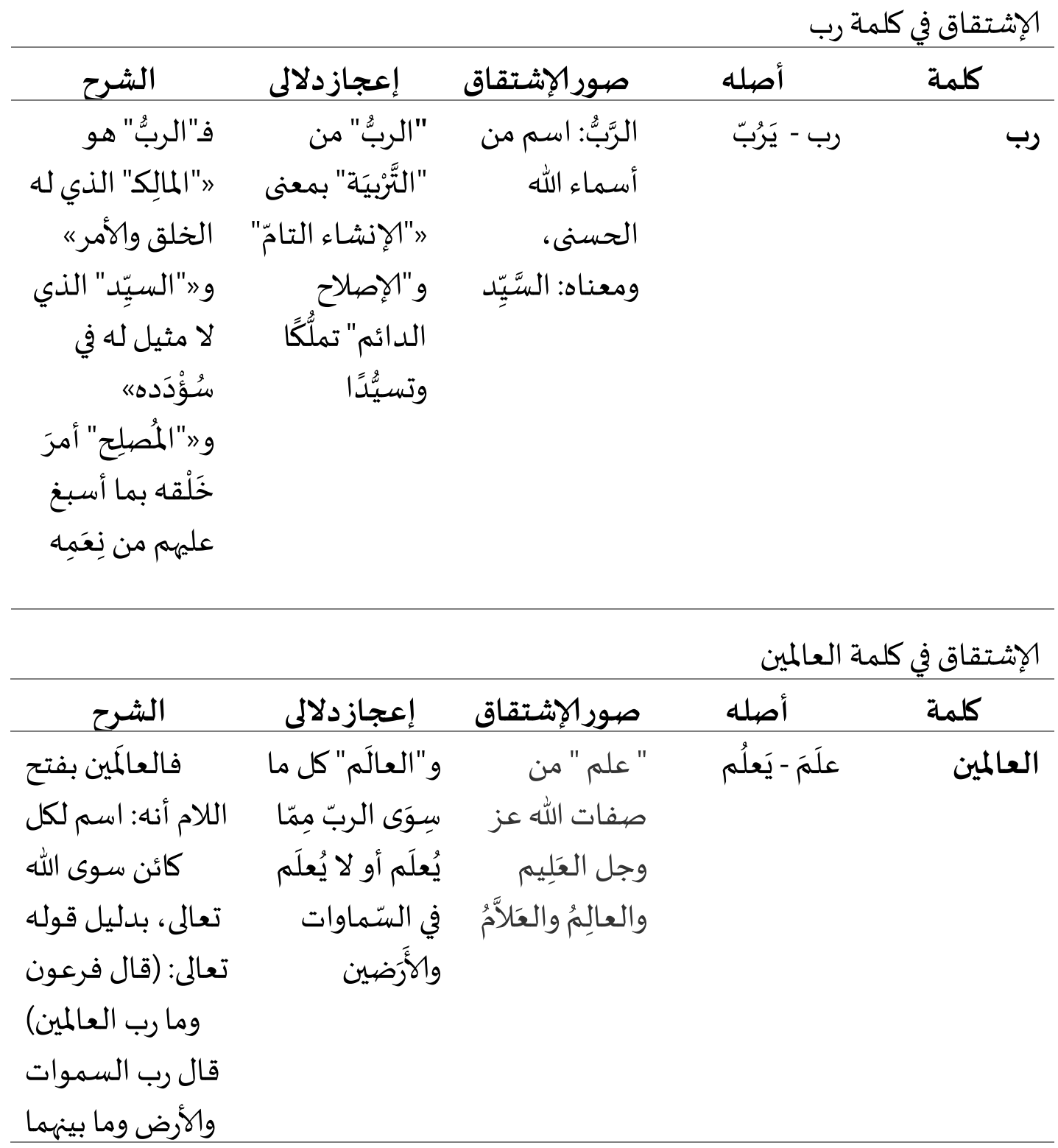

\section{'A Jamiy Jurnal Bahasa dan Sastra Arab}

Volume 08, No. 2, September 2019 ISSN: 2252-9926 (Print), ISSN: 2657-2206 (Online) 


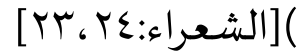

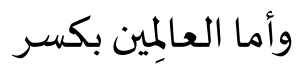

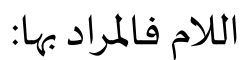

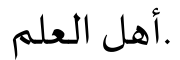

\begin{tabular}{rrr}
\hline & & \\
\hline \\
\hline
\end{tabular}

\section{'A Jamiy Jurnal Bahasa dan Sastra Arab}

Volume 08, No. 2, September 2019 ISSN: 2252-9926 (Print), ISSN: 2657-2206 (Online) 


$$
\text { الأشياء }
$$

\begin{tabular}{|c|c|c|c|c|}
\hline & & & \multicolumn{2}{|c|}{ الإشتقاق في كلمة يوم الدين } \\
\hline الشرح & إعجازدلالى & صورالإشتقاق & أصله & 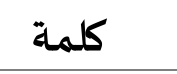 \\
\hline ويوم الدين & وآختيار لفظ & - ل - لَيَوْمُ :زمنْ & - - ميومُ أَيومُ & 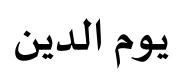 \\
\hline يوم الحساب & "الدِّين" راجع & مِقد اروه من & - - مان & \\
\hline للخلائق ، وهو & إلى أنّا يَشَمل في & طُلوع & يدين & \\
\hline يوم القيامة & دَلالتهاه معاني & الشـمس إِلى & & \\
\hline يدينهم & "الطّاعة" & غروبها & & \\
\hline بأعمالههم إن & و"الخضوع" & - - الديانة. & & \\
\hline خيرا فخير وإن & & معنى الدين & & \\
\hline شرا فشر ، إلا & & اسمَّ لجميع & & \\
\hline من عفا عناه & & ما يُعبد بـه & & \\
\hline
\end{tabular}

\section{'A Jamiy Jurnal Bahasa dan Sastra Arab}

Volume 08, No. 2, September 2019 ISSN: 2252-9926 (Print), ISSN: 2657-2206 (Online) 
181

الإشتقاق في كلمة إيّاك نعبد

\begin{tabular}{|c|c|c|c|c|}
\hline الشرح & إعجاز دلالى & صور الإشتقاق & أصلاه & كلمة \\
\hline إيّاك نعبد يعني: & نخصيُك & العبد : الإنسـان & عبَدَ - يَعبُد & إيّاك نعبد \\
\hline إيّاك نوحِّد & بالعبادة، & ، حرًّاً كان أَو & & \\
\hline ونخاف ونرجو يا & ونخصك & رقيقاً ، يُذْهَبُ & & \\
\hline رِّنا لا غيرك & بالاستعانة، لا & بذلك إِلى أَناه & & \\
\hline & نعبد غيرك & مربوب لباريها & & \\
\hline
\end{tabular}

الإشتقاق في كلمة إيّاك نستعين

\begin{tabular}{|c|c|c|c|c|}
\hline الشرح & إعجاز دلالى & صهور الإشتقاق & أصله & كلمة \\
\hline وَاعَيَّالكَ نَسْتَعِينُ : & ونحن بك & "نستعين"منك & استعانَ - & إيّاك ذسـتعين \\
\hline وإياك رَبنا & نستعين في & وحدك يا الله & يستعين & \\
\hline نستعين على & جميع أمورنا & نطلب العون & & \\
\hline عبادتنا إيّاك & مخلصين لك & & & \\
\hline وطاعتنا لك وفي & العبادة & & & \\
\hline أمورنا كلها -لا & & & & \\
\hline أحدًا سـواك، إذْ & & & & \\
\hline كان من يكفُر & & & & \\
\hline بك يَستعين في & & & & \\
\hline أمورِه معبودَه & & & & \\
\hline الذي يعبُدُهُه من & & & & \\
\hline الأوثان دونَك & & & & \\
\hline
\end{tabular}

\section{'A Jamiy Jurnal Bahasa dan Sastra Arab}

Volume 08, No. 2, September 2019 ISSN: 2252-9926 (Print), ISSN: 2657-2206 (Online) 
182

الإشتقاق في كلمة صراط

\begin{tabular}{|c|c|c|c|c|}
\hline الشرح & إعجازدلالى & صورالإشتقاق & أصله & كلمة \\
\hline صراط :هو كل & والصراط & الصراط، & السراط & صراط \\
\hline ممر بين نقطتين & عموما هو & ومعناها الجسر & & \\
\hline متنـاقضـين & العدل المطلق & الممدود & & \\
\hline كضفتي هر أو & لله تعالى وما & & & \\
\hline قمتي جبلين أو & عداه فهو نسبي & & & \\
\hline الحق والباطل & & & & \\
\hline والضلالة & & & & \\
\hline والهداية في & & & & \\
\hline الاسلام او الكفر & & & & \\
\hline والإيمان & & & & \\
\hline
\end{tabular}

الإشتقاق في كلمة المستقيم

\begin{tabular}{|c|c|c|c|c|}
\hline الشرح & إعجاز دلالى & صورالإشتقاق & أصله & 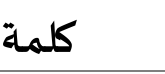 \\
\hline مُستقيمةًَ،، كأنّ & الاستقامة" لا & إِسنتِقِامَة : مِنَ & قيم - يقيم & المستقيم \\
\hline "الهداية" & تتمّّ إلّا إذًا & اعْبِد الِلهِ ، & & \\
\hline أصبحت شأنًَا & تفرَّقتِ السُبُّل & إِسنتِوائِهِ & & \\
\hline بَشَرِّاًا خالصيا & بالعباد وذهب & & & \\
\hline ولمَ تَعُدْ من & بهم التّنازُّع & & & \\
\hline \multicolumn{5}{|l|}{ آختصاص اللّه } \\
\hline سبحانا & & & & \\
\hline
\end{tabular}

\section{'A Jamiy Jurnal Bahasa dan Sastra Arab}

Volume 08, No. 2, September 2019 ISSN: 2252-9926 (Print), ISSN: 2657-2206 (Online) 
183

الإشتقاق في كلمة المغضوب

\begin{tabular}{|c|c|c|c|c|}
\hline الشـرح & إعجازدلالى & صور الإشتقاق & أصله & كلممة \\
\hline المغضيوب عليهم & المغضوب عليهم & الغَضَتَبُ : & غضِبَ - & المغضوب \\
\hline لأنهم هم: اليهود & هُم كل الذين & نَقِيضُ الرِضِيَا & يَغضَبَ & \\
\hline عصيوا على & أتاهم هُدى اللّه & & & \\
\hline بصيرة؛ معهم & فأبوا إلّا أن & & & \\
\hline علم ولم يعملوا & يكذبوا باه ظلْمَا & & & \\
\hline باه & وعدوانا. & & & \\
\hline
\end{tabular}

الإشتقاق في كلمة الضالين

\begin{tabular}{|c|c|c|c|c|}
\hline الشرح & إعجازدلالى & صور الإشتقاق & أصله & كلمة \\
\hline والضيالون هم: & ـ الضـالِّنِن هُم & "ضـال" : السَّـدْرُ & ضلَّ يضلّ & الضيالين \\
\hline النصـارى لأنهم & كل الذين طلبوا & البَرِيّيٌ & & \\
\hline يتخبطون في & الصِّراط & & & \\
\hline العمل، & المُستقيم & & & \\
\hline فيعملون على & فأضيلَّتهُم كثرةُ & & & \\
\hline جهل وضلال & الشُبُهُات وآتَّبَعَوا & & & \\
\hline & نوازع الأهواء & & & \\
\hline
\end{tabular}

\section{'A Jamiy Jurnal Bahasa dan Sastra Arab}

Volume 08, No. 2, September 2019 ISSN: 2252-9926 (Print), ISSN: 2657-2206 (Online) 
أن مفهوم الإشتقاق الألفاظ في سورة الفاتحة يحتوي على ثلاثة أقسام : الإشتقاق الصغير / عام ("مَلك" و"مَلْكَ" بتخفيف اللّام و "مالِكَ" اسم الفاعل من "مَلَكَ" ) و الإشتقاق الكبير ( حمد - مدح ) و الإشتقاق الأكبر ( السراط - الصراط ).و إعجاز المعاني الألفاظ الإشقاقية في سورة الفاتحة يحتوي علي أربعة أقسام : إعجاز البلاغي:( ملك يوم الدين ) ثم إعجاز العلمي : ( غير المغضوب عليهم و لا الضالين ) و إعجاز تشرعي : ( إياك نعبد و إياك نستعين ) و إعجاز عدد : ( الحمد, الله, رب, العالمين, الرحمن, الرحيه, يوم, الدين ).

\section{المراجع}

أ. د. فهد بن عبد الرحمن بن سليمان الرومي, دراسـات في علوم القرآن الكريم, (حقوق

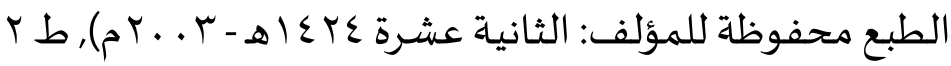

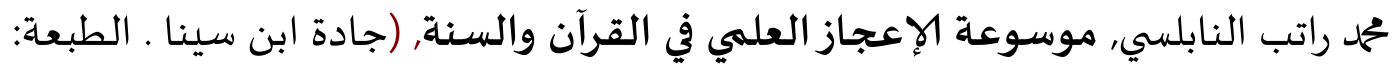

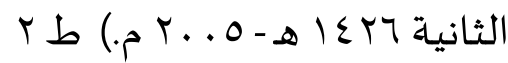

الدكتور فريض عوض حيدر، علم الدلالة دراسة نظرية تطبيقية، (القاهرة، مكتبة النهضية

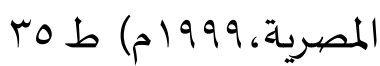

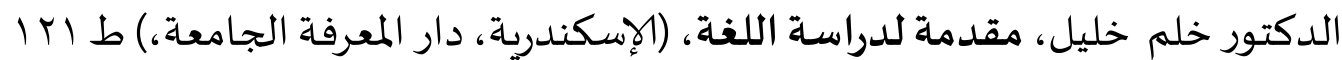
الدكتور فريض عوض حيدر، علم الدلالة دراسـة نظرية تطبيقية، (القاهرة، مكتبة النهضية

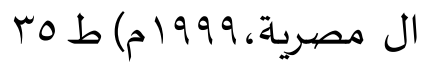

الدكتور فريض عوض حيدر، علم الدلالة دراسـة نظرية تطبيقية، (القاهرة، مكتبة النهضة

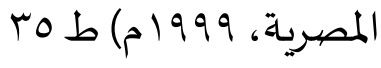

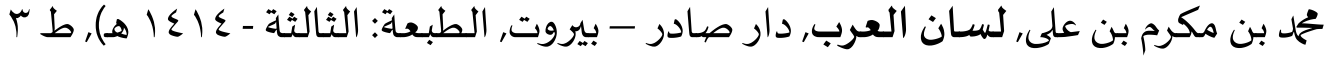

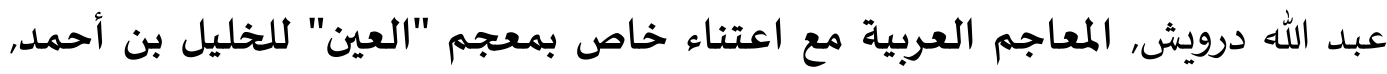

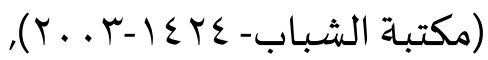

أبو نصر إسماعيل بن حماد الجوهري الفارابي, الصحاح تاج اللغة وصدحاح العربية العبابة, (دار

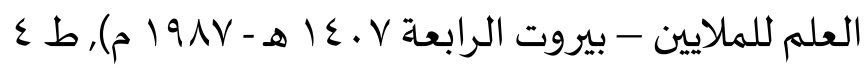

\section{'A Jamiy Jurnal Bahasa dan Sastra Arab}

Volume 08, No. 2, September 2019 ISSN: 2252-9926 (Print), ISSN: 2657-2206 (Online) 
185

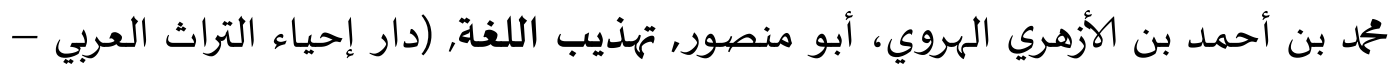

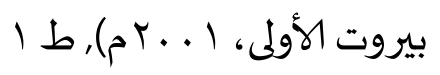

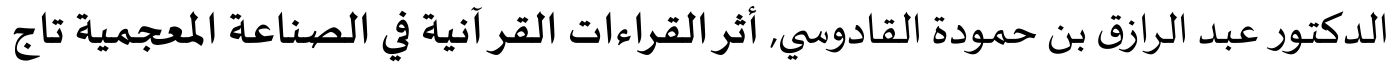

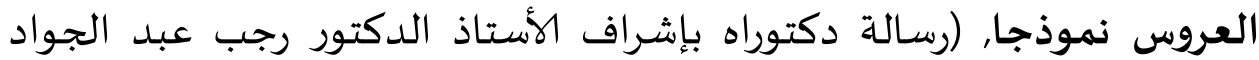

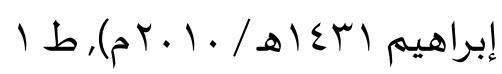

محمد بن أحمد بن الزٔهري الهروي، أبو منصور، تهذيب اللغة الغة، (دار إحياء التراث العربي -

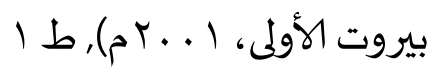

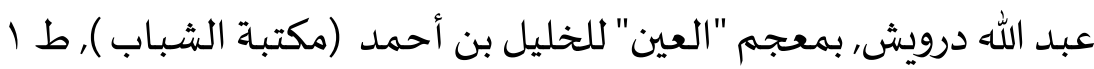

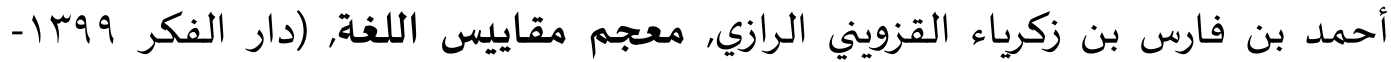

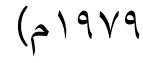
عبد الرحمن بن أبي بكر, المزهر في علوم اللغة و أنواعها, دار الكتب العلمية - بيروت, الأولى،

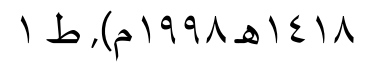

السنة معجم لغوي, من أسرار اللغة في الكتاب والسنة معجم لغوي ثقافي, المكتبة المكية -

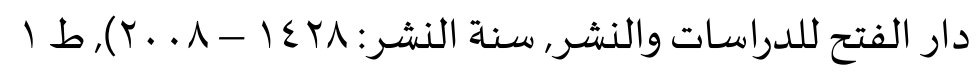

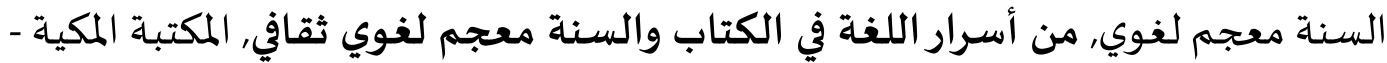

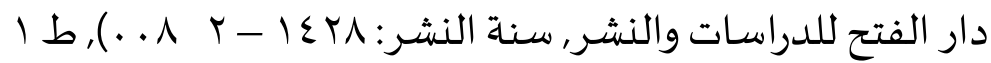
عبد الرحمن بن أبي بكر, المزهرفي علوم اللغة و أنواعها, دار الكتب العلمية - بيروت, الأولى،

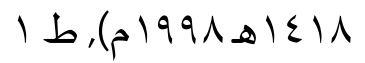

أحمد بن فارس بن زكريا الرازي أبو الحسين, الصاحبي في فقه اللغة العربية ومسائلها

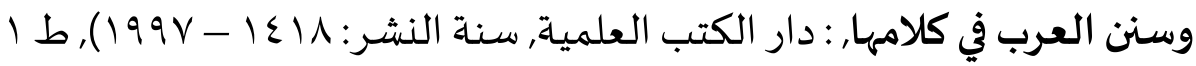

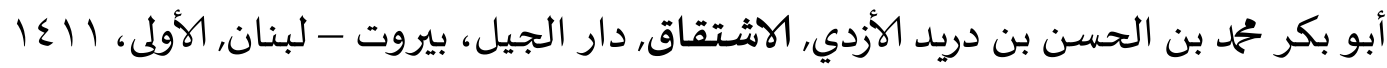

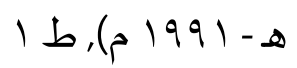

أبو حيان محمد بن يوسف بن علي بن يوسف بن حيان الثيان أثير الدين الأندلسي, البحر المحيط في

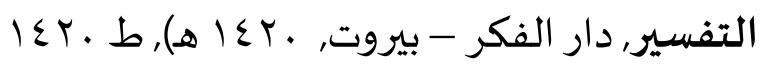

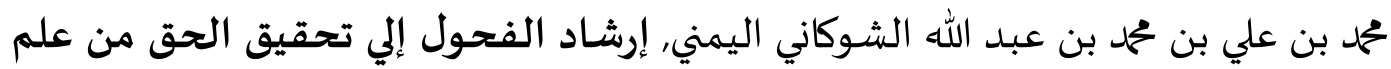

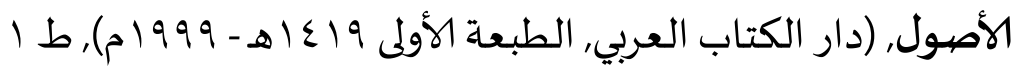

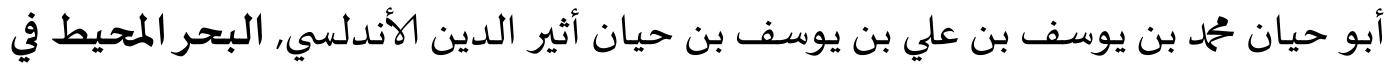

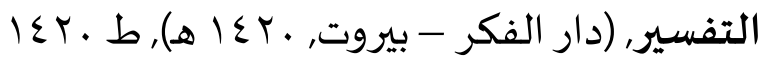

\section{'A Jamiy Jurnal Bahasa dan Sastra Arab}

Volume 08, No. 2, September 2019 ISSN: 2252-9926 (Print), ISSN: 2657-2206 (Online) 
186

عبد الرحمن بن أبي بكر، جلال الدين السيوطي, المزهرفي علوم اللغة و أنواعها, (دار الكتب

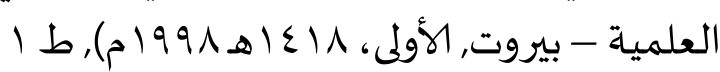

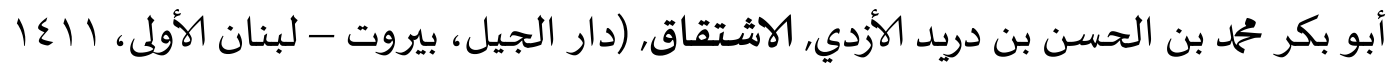

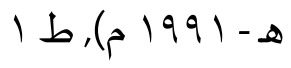

عمرو بن عثمان بن قنبر الحارثي بالولاء, الكتاب سيوبية, (مكتبة الخانجي، القاهرة, الثالثة،

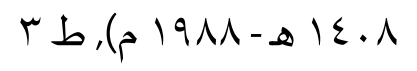

عبد الغنى الدقر, معجم القواعد العربية في النحو و التصريف ( دار القلم - الدمشق ا ط ط (1917-) - ع.7 